\title{
MULHERES NOS CONTOS OITOCENTISTAS DA IMPRENSA PERIÓDICA PORTUGUESA*
}

\author{
Simone Cristina Mendonça
}

\begin{abstract}
RESUMO: Em meio a notícias, curiosidades, História e biografias, alguns jornais portugueses do início do século XIX, imprimiram narrativas ficcionais, às vezes divididas em vários números, nas quais é possível destacar a presença de personagens femininas. Especificamente no periódico O Mosaico, publicado em 1839, encontramos cinco protagonistas, cujas histórias apontam para os sofrimentos das mulheres em não conseguirem realização amorosa ante as convenções oitocentistas do casamento. O presente artigo visa lançar luz sobre tais convenções e refletir sobre como os leitores da época recebiam essas narrativas.
\end{abstract}

Palavras-chave: contos, personagens femininas, século XIX.

O periódico português O Mosaico. Jornal d'Instrucção e Recreio foi publicado pela Imprensa Nacional a partir de 1839, trazendo como "Proemio" 1 do número 1, o alerta: "Poesia e litteratura, (1) e romances comporão as paginas do nosso jornal, e buscaremos pôr entre as variadas côres do = MOSAICO = introduzir, quanto possível, a instrucção, e o deleite, o util, e o agradavel". O numeral entre parênteses remete para uma nota de rodapé em que se defende a inserção do Romance: "Este genero de litteratura, com quanto mais ligeiro, não merece ser desdenhado, porque em suas formas bellas, e graciosas mesmo o litterato consumado colhe bem apreciaveis idéas. Os Romances historicos serão preferidos".

A nota antecipa possíveis críticas à seleção dos conteúdos literários, como se antevisse a necessidade de uma defesa prévia da inserção do gênero já benquisto nas páginas de tantas outras folhas periódicas de Portugal, país que testemunhou um significativo aumento de jornais e revistas a partir de

* O conteúdo deste artigo faz parte de uma pesquisa de Pós-doutorado realizada junto ao IBILCE/Unesp, entre 2015 e 2016. Uma versão preliminar deste texto foi apresentada sob forma de participação em mesa redonda no evento: Ciclo de debates "Literatura, Linguagens e Interfaces: desafios, possibilidades e perspectivas", realizado no dia 21 de fevereiro de 2017 , sob organização da Faculdade de Educação do Campo, na Unifesspa - Univ. Federal do Sul e Sudeste do Pará.

${ }^{1}$ Serão respeitadas nas citações a ortografia e a pontuação das fontes primárias consultadas. 
1750 (Cf. VELOSO, 1987, pp. 30-31), período em que também já se tem notícia de impressão e circulação de obras em prosa de ficção (Cf. TENGARRINHA, 1989 , p. 56).

Nos primeiros anos do Oitocentos, com o impulso do número de periódicos impressos (Cf. VELOSO, 1987, pp. 31-2), verifica-se a presença de considerável número de textos em prosa de ficção estampados nas páginas de jornais e revistas, como exemplifica Ernesto Rodrigues (1998) no estudo Mágico folhetim, citando os títulos de O Redactor, ou Ensaios Periódicos de Litteratura, e Conhecimentos Scientíficos Destinados Para Illustrar A Nação Portugueza (1803) e Analecto de Recreação e erudição (1805) como "títulos pilares" nos quais "podíamos assentar a estratégia do revistismo literário" ( $p$. 110). De acordo com o mesmo autor, ainda no ano de 1802 já se encontravam as primeiras publicações em capítulos de narrativas de ficção em Portugal, quando estreia o término do texto com a fórmula "Continuar-se-ha", no periódico Novidades Literárias (RODRIGUES, 1988, p. 209).

A fórmula acima nos remete ao tema do folhetim como fenômeno da imprensa periódica, já bastante estudado em pesquisas clássicas e atuais que versam sobre a publicação de romances em capítulos separados, no rodapé dos jornais oitocentistas, como as de Meyer (1996) e Thérenty (2015), para citar apenas duas referências em português. Nossa atenção volta-se especialmente para presença de tal prática em Portugal, na primeira metade do século XIX.

No mosaico de conteúdos apresentados pelos periódicos para os leitores portugueses das primeiras décadas do Oitocentos, também se encontram artigos científicos, passagens históricas, curiosidades, informações diversas e textos menos sérios, de caráter ficcional, destinados ao lazer, mesclados, sem compromisso, como se se quisesse instruir e deleitar ao mesmo tempo. O consumidor dos jornais e revistas ia adquirindo, assim, meio que por osmose, conhecimentos variados, sem grandes reflexões e longo tempo destinado aos estudos, sem dar-se conta, uma vez que tinha acesso a textos relativamente curtos, com linguagem menos rebuscada, entremeados de narrativas, também de poucas páginas, ou ainda divididas em capítulos a serem publicados subsequentemente.

Retomando o texto de abertura de O Mosaico, vemos que seus redatores certamente prezavam pelas "apreciáveis idéas" vindas do "Romance", mas, compreendamos, daqueles selecionados, preferencialmente dos históricos, que pudessem contribuir com o recreio dos leitores, sem lhes ferir os preceitos morais.

Além das narrativas ficcionais, chamadas n'O Mosaico de "Romance", também se imprimiam biografias, poesias, descrições de cidades, máximas e pensamentos, anedotas, "scenas d'historia", textos divulgadores de ciências, "Contos juvenis" e trechos de peças teatrais. Os artigos e os textos literários poderiam vir, ainda, acompanhados de ilustrações, que contribuem para o entretenimento e a apreciação estética. Os muitos títulos literários presentes 
vêm seguidos pela indicação do gênero (Poesia ou Romance), classificação que pode auxiliar ou confundir o leitor-pesquisador da atualidade.

Para o presente estudo, foram selecionadas cinco publicações presentes na rubrica "Romance", que trazem como protagonistas personagens femininas às voltas com angústias, desesperos e até com a morte decorrente da infelicidade conjugal e da impossibilidade de realização de anseios amorosos. Como é de se esperar, mantém-se nos contos selecionados as temáticas do casamento arranjado pelos pais (envolvendo questões financeiras), dos amores fora do casamento quase sempre impossíveis de serem realizados e da valorização da imagem do homem, como o condutor dos destinos das mulheres, estas frágeis e com possibilidades mínimas de realização na vida e no amor. A exaltação da imagem masculina chegará ao extremo no último conto comentado.

Logo em seu primeiro número, esse jornal traz um capítulo do romance "Vannina d'Ornano", que será contemplado com outros capítulos nos números 2 e 3. A personagem que dá nome à história ficcional é uma mulher de elevada posição social, com "seu pállido e magestoso semblante; seus olhos côr de Ebano" (p. 04)2, da qual são comentados alguns traços do caráter psicológico, aparentemente abalado pela falta de notícias quanto a uma guerra, na qual se encontra seu esposo, Sampietro, há 15 dias.

Uma desconfiança de traição, relativa à fidelidade à pátria e à família, envolve os pensamentos da nobre personagem, acrescida pelos dizeres mordazes de uma criada, chamada Maria. Há um diálogo entre ambas na cena inicial, que nos revela outros personagens, como os filhos de Vannina e um homem a quem ela amou na juventude, Vivaldi, tendo sido o romance entre eles proibido pelos irmãos da protagonista, os quais a entregaram para casarse com um estrangeiro.

À chegada do esposo, o leitor conhece um "guerreiro", que "tirou o capote em que vinha ambuçado, mostrando seu gibão azul, e duas pistolas à cintura, e a mão direita encostada ao punhal" (p. 22). Contrariando a imagem de fragilidade com que até então Vannina havia sido descrita, pois muitas lágrimas derramara, tremendo ante a violência com que Sampietro a tratava, no terceiro capítulo, intitulado "Caso horrível", a protagonista tem forças para levantar-se contra o marido, enfrentando-o em sua defesa e de seus filhos, contra os quais ele avança de forma ameaçadora.

Em movimento oposto, a personagem Maria, que antes não continha suas palavras para acusar sua senhora, relembrando-a de suspeitos atos passados, agora, temerosa de que Sampietro pudesse ferir Vannina, assume uma posição subserviente, tentando apaziguar os ânimos exaltados de seu patrão.

\footnotetext{
2 Esclarecemos que o número da página constante entre parênteses logo após o excerto do jornal refere-se ao informado no periódico o Mosaico (1839), cuja paginação é contínua de um número para outro, provavelmente como forma de facilitar a posterior encadernação, tal como se dá no volume disponível no site do projeto temático "O real em revista" (www.orealemrevista.com.br), no qual se encontra uma versão digitalizada do periódico.
} 
Ambas as mulheres, aqui, apresentam uma mudança de personalidade, um novo comportamento diante do medo causado pela violência das palavras e dos gestos e, mesmo, pela própria aparência de um homem que se coloca em posição de superioridade. Nessa mudança, Vannina desponta com maior vigor, já que, ao receber acusações injustas e ver seus filhos ameaçados, consegue tomar atitudes antes impensáveis.

Conhece-se, por meio dos gritos de Sampietro, que, por motivo de guerra entre sua pátria e a de seu esposo, Vannina perdera muitos de seus bens, móveis e imóveis, e tentara recuperá-los, solicitando-os à República, fato que a desonrava na visão do esposo. Ademais, Vannina é surpreendida pela leitura de uma carta-resposta de seu antigo amigo, Vivaldi, inimigo de Sampietro, resgatada de um mensageiro, em que se comprova um plano de fuga e traição, desta vez, amorosa. Tomado de fúria, o marido que iria ser traído declara que Vivaldi a esta altura já estava morto, por suas mãos. Encolerizado, Sampietro também dá cabo da vida de Vannina, enforcando-a.

A última página do número 16 do periódico, como de costume, traz uma grande e cuidada ilustração que remete para o romance intitulado "Júlia", o qual abrirá o número 17 , estreando na primeira página do jornal, em que a rubrica "Romance" ocupa lugar de destaque, logo abaixo da costumeira "Analyse da Estampa" (p. 129). (Ver Figura 1).

Figura 1: ilustração para o Romance "Júlia”, do n. 17. de O Mosaico

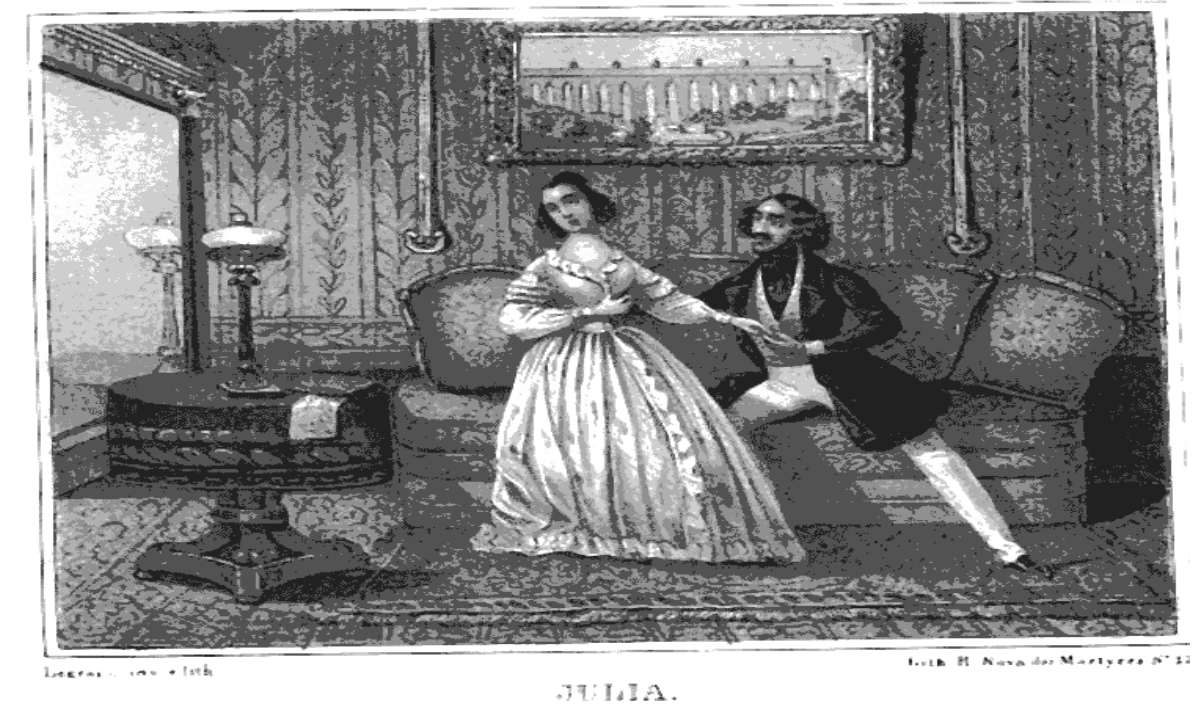

disponível em:

$<$ https://books.google.pt/books?id=K8Y_AAAAYAAJ\&printsec=frontcover\&hl=ptpt\&source=gbs_ge_summary_r\&cad=0\#v=onepage\&q\&f=true>. Consulta em 14/03/2016.

A cena ilustrada no último exemplar do mês de maio (um homem suplicando algo à Júlia, em uma sala) revela a história de Guilherme, concunhado da protagonista, a quem foi designado que descobrisse qual segredo tanto entristecia a bela personagem central, que já se encontrava 
doente. O esposo, Fernando, não havia conseguido decifrar o mistério que lhe carregava a vida da mulher amada. A confissão de Júlia surpreende o confidente, ao revelar-lhe seu amor até aquele momento mantido em oculto, por respeito ao matrimônio de Guilherme com sua cunhada e ao casamento negociado com Fernando para fins materiais, tendo em vista que Júlia era órfã.

O amor impossível, acrescido pela certeza de não poder fazer feliz o esposo, levara Júlia a tamanho tormento, que desfalecia. Se para o leitor contemporâneo, a enfermidade da personagem soa como exagero de emoções, sendo os arroubos sentimentais vistos com certo ar de humor, para o leitor ou o ouvinte da época as lágrimas, a palidez, os suspiros e até os desmaios, vinham tornar mais fascinante a história de amor, que caminhava para uma tragédia, como a anunciada por Júlia: "Ah! Feliz será o dia, que me livre do fardo da existencia. Imploro constantemente a morte, como um condemnado a pede no meio dos tormentos... Ella me ouviu, Guilherme, e dentro em pouco serei feliz..." (p. 131).

Durante a confissão, alguns pormenores vão tornando a narrativa mais clara, como a frequência de Guilherme na casa da tia de Júlia, onde se conheceram, informando, inclusive, locais como as cidades de Lisboa e Sintra. Alguns indicativos do tempo, marcado pelas batidas do "relógio de São Vicente" (p. 129), auxiliam o acompanhamento da cena, reveladora da complexidade da personagem, atormentada pelo pecaminoso desejo de adultério, pelo reconhecimento de sua incapacidade de omissão dos fatos e pela aspiração à morte, como fuga de suas angústias.

Corações palpitantes e respiração acelerada, eis que o confidente beijaIhe os lábios, exclamando: "eu te amo de todo o meu coração" (p. 131), e a dama de "olhos côr de ebano" (p. 129) desmaia, golfando sangue pela boca. Fernando é chamado e declara tudo ter ouvido. Não poderia haver momento mais propício para a suspensão da história, no auge das emoções de personagens e leitores, curiosos pela continuação, porém, não é o que ocorre. Tudo se encerra com a conclusiva declaração: "Ah! sim bem desgraçados que na manhã seguinte ambos chorámos !!! ..." (p. 132), que apenas permite ao leitor assimilar que Guilherme e Fernando lamentariam a morte de Júlia, recurso (bastante limitado) que o autor encontrou para solucionar o triângulo amoroso que se formava. Ante preceitos morais vigentes, censores alertas e a necessidade de agradar aos leitores fiéis e aos redatores dos jornais, apenas a morte poderia ser utilizada para livrar a protagonista do malquisto adultério anunciado.

Após pequeno intervalo, a rubrica "Romance" reaparece no número 26, cujo final traz, novamente, uma cena de um romance, em que figura uma tentativa de assassinato, criando expectativas para a "Analyse da estampa" que abrirá o exemplar da próxima segunda-feira. Eis, então, que a rubrica "Romance" retoma sua posição de destaque na primeira página, trazendo a história de "Christina", que ocupará 6 páginas de um mesmo número. (ver Figura 2). 
Figura 2: cena do Romance "Christina", do n. ${ }^{\circ} 28$ de O Mosaico

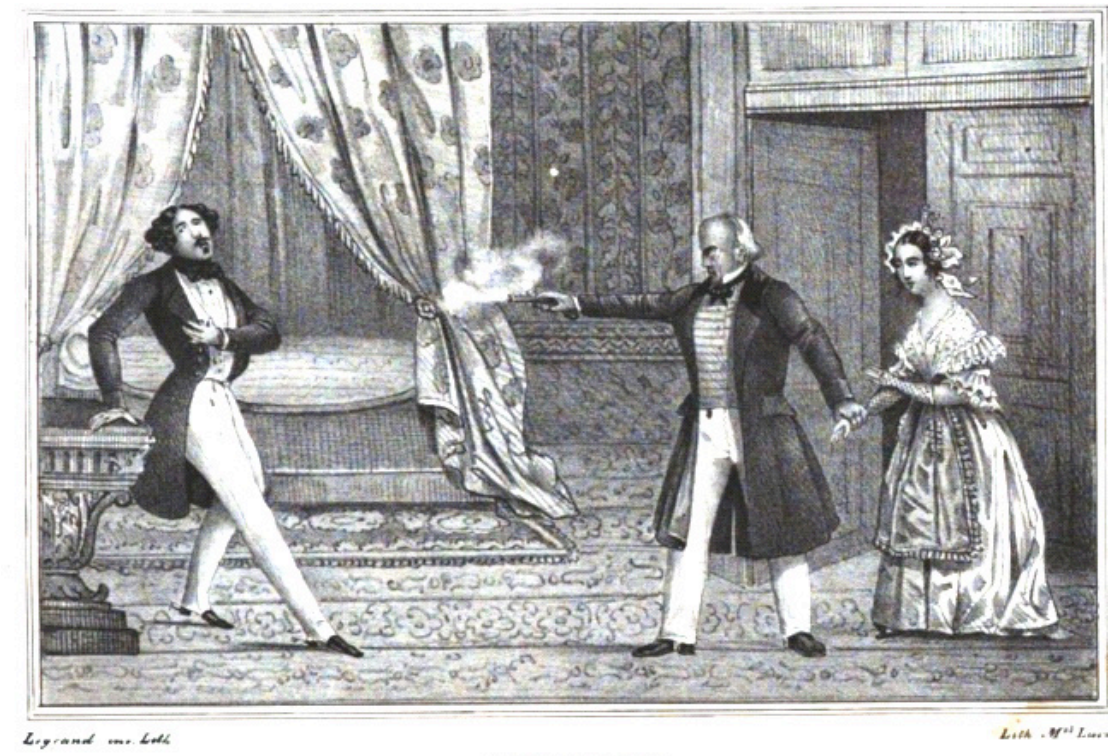

CHRISTINA

Disponível em:

$<$ https://books.google.pt/books?id=K8Y_AAAAYAAJ\&printsec=frontcover\&hl=ptpt\&source=gbs_ge_summary_ $r \& c a d=0 \# v=$ onepage\&q\&f=true $>$ Consulta em 23/03/2016.

Órfã de pai, a rica Christina desenvolveu beleza e talentos admiráveis e, aos 15 anos, sentiu as inquietações do amor, apaixonando-se pelo "Marquez de ${ }^{* * *}$ (p. 225), o qual apenas a enganara. Entristecida e quase doente, Christina parte com Luiza, sua mãe, para Lisboa, onde viveriam na casa de um tio idoso e viúvo, "Pedro de M..." (p. 226). Riquezas, criados e todos os cuidados não foram suficientes para evitar a morte de sua mãe e tal perda, acompanhada do susto causado pela invasão do "Marquez" em seu quarto, levam a jovem a grave doença, como sempre sói acontecer com nossas sensíveis heroínas oitocentistas. $\mathrm{Na}$ tentativa de restabelecer a saúde da sobrinha, proporcionam-Ihe lazer: uma viagem para "Bemfica" (p. 227), livros, visitas ao "Theatro de S. Carlos" para ver "Guilherme Tell" e um baile de máscaras (p. 227), justamente no qual, auxiliado pelas fantasias parecidas, 0 "Marquez" conseguiu sequestrar Christina.

Pedro em vão procurou pela sobrinha e, após muitas ameaças de morte aos criados do "Marquez", conseguiu saber que a mesma se encontrava em "Chelas". Enquanto isso, a protagonista já havia desmaiado inúmeras vezes junto do "Marquez", que tentou socorrê-la, mas não obteve sucesso. O fato é que os constantes desmaios e as tentativas de recobro dos sentidos da moça acabaram por constituir-se como impedimentos para que o pérfido amante exercitasse sua paixão "furiosa" (p. 228) e a tomasse à força, desonrando-a, conforme seu intento.

O tempo, que no início era marcado pelos dias que se foram passando entre uma viagem e outra, e que parecia ficar quase em suspenso com a 
aflição do leitor ao acompanhar as manifestações físicas de susto, saudade e tristeza da protagonista; depois do sequestro passou a ser tão ágil quanto as rodas velozes da carruagem de Pedro à procura de Christina. No clímax da ação, quando o tio "Chega, arromba a primeira porta, que encontra, e dirige-se a camara onde estava Christina; tudo é obra de um momento" (p. 228). A agitação com que é contado o tempo aumenta com a grande movimentação das pessoas da casa após um tiro, já anunciado pela gravura: "Toda a casa se põe em movimento, toda a gente se reune contra Pedro (...)" (p. 228). Estamos no ponto alto da narrativa, com o perigo da morte do "Marquez".

No entanto, tudo volta a ser calmo, com o retiro de Christina e seu tio para uma quinta e o consequente acompanhamento em oculto que the fez o "Marquez" após curar-se da ferida causada pela bala. Longa carta de arrependimento, "dezesseis mezes" de retiro e a simplicidade da vida no campo transformam-no, surpreendentemente, num honesto amante aos olhos do leitor. Disfarçado de estrangeiro, com roupas de camponês, o Marquez não é percebido pelos vizinhos, Pedro e Christina, sendo que esta última passa a admirá-lo.

Note-se que a mudança de roupas, que dantes fora usada para um intento malévolo, serviria agora para tentar convencer a jovem de uma profunda e positiva mudança de caráter desse homem pelo qual há muito encontrava-se apaixonada. A estratégia de troca de roupas para ocultar um personagem, que passa a ser reconhecido ou não conforme o traje, utilizada comumente pelos autores do período, pode, ao leitor atual, conferir inverossimilhança ao texto, mas tal não ocorria com o leitor oitocentista, que observou que, em ambas as ocasiões, Christina não foi capaz de reconhecer o vilão/amante que sob as vestes trocadas se apresentava.

Um atentado à vida de Pedro, o socorro imediato vindo de um desconhecido que se fere e o reconhecimento de que o benfeitor tinha sido o próprio Marquez, em roupas camponesas, concluem a metamorfose do personagem antes antagonista da história, que rouba doravante as cenas do romance com convalescência, pedido de perdão, melhoria da saúde e matrimônio com Christina, no desfecho do enredo.

$E$, mantendo-nos no campo semântico do matrimônio, encontramos a imagem de "Yolande de Rocmartine", uma jovem vestida de noiva, imagem esta que fecha o exemplar de jornal, anunciando o romance homônimo a sair no número 42, entre as páginas 329 e 335. 
Figura 3: "Yolande de Rocmartine", do n. ${ }^{\circ} 42$ de O Mosaico

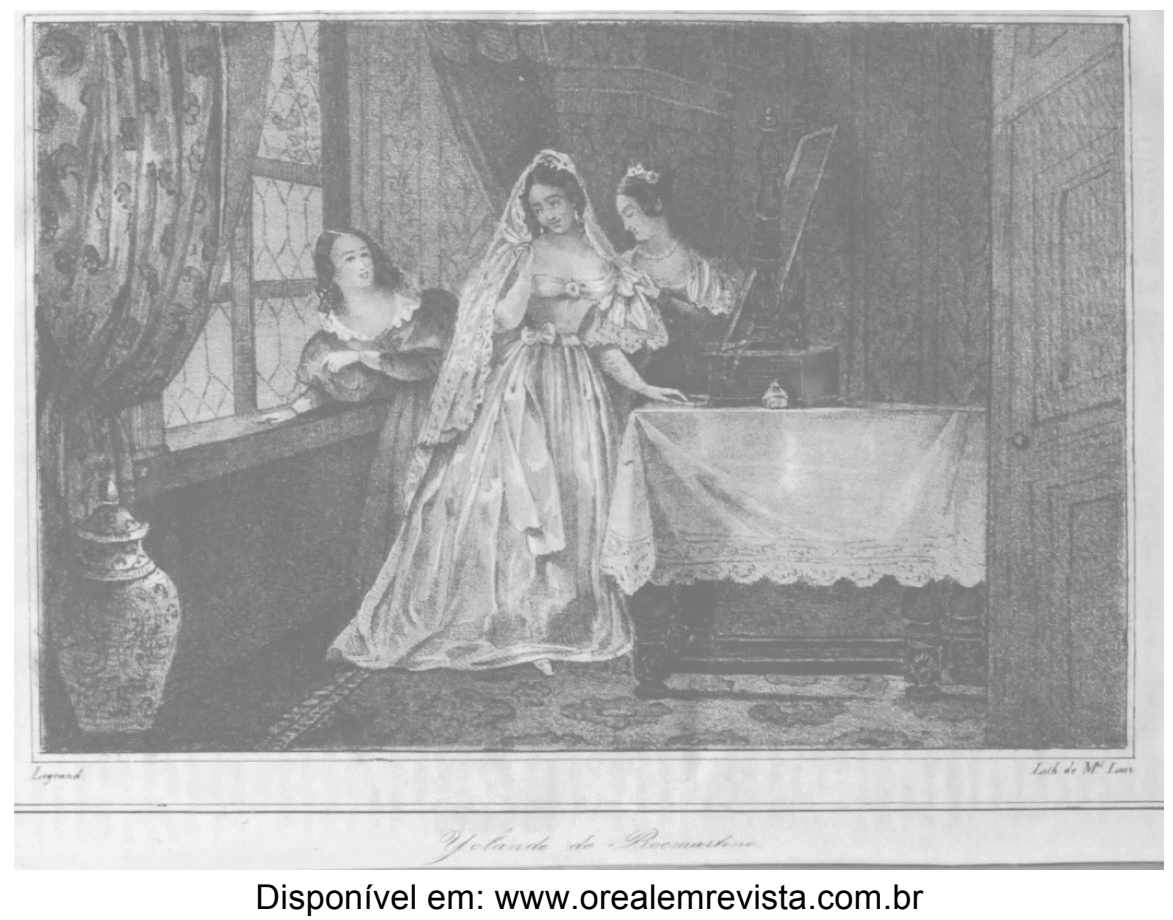

De extensão um pouco mais longa que a costumeira, a triste história de Yolande, passada no interior da França, nos revela um casamento arranjado por sua mãe para salvar o pequeno patrimônio que lhes restava. $O$ noivo de meia idade em nada se fazia aprazível aos olhos da jovem, de apenas 18 anos, que já se encontrava apaixonada pelo moço Elzeard.

Felizmente, poucos meses separaram os jovens, cujo amor poderia tê-los encaminhado para o adultério, graças a um ataque apoplético sofrido pelo Conde, que tornou Yolande viúva e liberta para um novo consorte. Note-se que, nesse conto, com desfecho mais auspicioso para a protagonista, foi o fim da vida do cônjuge que a salvou de dar um mau passo em sua vida matrimonial. No entanto, mantiveram-se intactos os laços dos casamentos arranjados pelos pais e irmãos, tal como ocorreu com as personagens Júlia e Vannina, casamentos aos quais essas mulheres foram fiéis, a muito custo, até que a morte as separasse dos maridos.

E ficamos pensando que tudo se articula com tranquilidade nos casos de amor das histórias do Mosaico, sempre respeitosos de moral e dos bons costumes até que encontramos "As duas rivaes" (pp. 337-340), o qual fecha o conjunto de contos publicados na rubrica "Romance" do ano de 1839, no número 43, logo após uma gravura ilustrando o número anterior. De cenário e tempo distantes, a história vinda do século XIII descreve uma paixão iniciada em meio a uma batalha contra muçulmanos, na qual a filha do sultão, Leila, é raptada pelo moscovita Conde de Gleichen, que logo é preso pelos sarracenos.

O desequilíbrio das nossas impressões sobre os contos oitocentistas desse semanário é causado pelo fato de que, malgrado ser o conde um 
homem casado, os originais amantes, de religião e cultura tão díspares, maquinam uma fuga que, bem sucedida, os leva à Veneza. Questões apenas de ordem religiosas se colocam no destino do conde, que, antes mesmo de pensar em sua mulher, procura as autoridades para pedir permissão para levar Leila como sua segunda esposa. Curiosamente, verificamos que, mediante promessa de conversão da muçulmana, ele consegue autorização para manter as duas mulheres em seu leito.

Surpreendem-nos os indicativos dos muitos privilégios de que gozavam os homens do século XIX, até mesmo nas narrativas ficcionais, em relação às sofredoras protagonistas, insultadas, violentadas ou que até morriam pelo complexo tormento de não poder ver realizados seus amores, presas a imposições familiares. Na narrativa deste número, por exemplo, lemos que curiosa cumplicidade se estabeleceu entre "as duas rivaes" desta bigamia permitida, em paisagens exóticas e com episódios sensacionalistas, sem prejuízos para a recepção da história e a circulação de $O$ Mosaico.

Tendo falecido no desfecho ambas as esposas do Conde de Gleichen, encontramos, com o inusitado comentário do narrador intruso, a possível explicação para o triângulo amoroso bem-sucedido e aproveitado pelo conde:

\begin{abstract}
Pobre Leila! tua belleza repousa em solo estranho. Não tornarás a vêr mais brilhante o sol, e as verdes palmeiras de teu Reino; e tua vida tão esplandecente à nascença se extinguiu nos nevoeiros, e gelos da Russia! Teu amor mesmo não obteve a mais suava recompensa, por que elle foi esteril. Porém consola-te, pois praticaste na mais sublime pureza os preceitos d'uma religião, que tomara em conta todos os sacrificios, e te abrirá as portas do Ceu !!! (p. 340).
\end{abstract}

Assim termina o conto cercado das curiosidades sobre as pessoas vindas do oriente, que transgrediu as regras matrimoniais da época e, calmamente, deu fim à vida da filha do sultão, por amor ao esposo convertida para uma religiosidade diversa.

Diferentemente das protagonistas dos contos analisados anteriormente, que enfrentaram as vicissitudes de amores proibidos, caladas pelas normas sociais, constatamos que o personagem masculino de "As duas rivaes" nenhum tormento psicológico sofreu diante da possibilidade de realizar uma paixão extraconjugal. Hierarquicamente superior a sua primeira esposa, nem sequer minimamente reflete sobre qual seria a reação dela, que, submissa, aceita o que lhe impõe o marido, convivendo pacificamente com aquela que poderia ser tomada como sua inimiga. O homem, neste conto, concretiza seus desejos, ampliando suas possibilidades de relacionamento amoroso, sem encontrar opositores, já que nem mesmo foi condenado pelas autoridades religiosas.

Talvez, justamente por localizar a história em tempo e espaço tão distantes do contexto oitocentista português, o autor tenha conseguido 
conquistar os leitores, que pouco questionariam os episódios incomuns, ainda mais que justificados pela conversão da muçulmana.

Ao findar nossa consulta aos contos, novelas e histórias d' O Mosaico, publicados em 1839 na rubrica "Romance", ficamos a nos perguntar sobre as impressões dos leitores acerca das histórias de amor, angústia e dor que os acompanharam ao longo do ano, sem conseguirmos respostas concretas, pois nem mesmo pudemos contar com uma seção de cartas no periódico que nos trouxesse um indício das opiniões dos leitores.

Entre dúvidas e suposições, fica a certeza de que a presença dos textos em prosa de ficção em bastantes títulos de periódicos portugueses, estendendo-se ao longo de décadas na primeira metade do século XIX, conquistando cada vez mais espaço entre os editores de jornais e revistas e saindo à luz com divisões que chamavam para o próximo número a ser publicado, deve significar que eram agradáveis aos leitores.

Cremos que os portugueses oitocentistas interessaram-se cada vez mais em adquiri-los, lê-los, privativamente ou, quem sabe, de forma coletiva, participativa, dando-se margem aos comentários em grupo. Os contos, novelas e histórias poderiam ser lidos em voz alta para um grupo, familiar, por exemplo, que aguardaria, em conjunto, a continuação de seu enredo.

Por fim, as impressões desses textos eram muitas vezes divididas, materialmente falando, pensando-se apenas nas continuações das narrativas em números seguintes dos periódicos. E, possivelmente, eram as impressões divididas, mudando-se a conotação, pensando-se nas conversas entre os leitores/ouvintes de suas histórias, suas opiniões trocadas, as críticas e sugestões enviadas por correspondência para os editores de outros jornais e revistas.

\title{
WOMEN IN THE EIGHTEENTH CENTURY SHORT STORIES OF THE PORTUGUESE PERIODICAL PRESS
}

\begin{abstract}
Among news, curiosities, history and biographies, some Portuguese newspapers of the early nineteenth century printed fictional narratives, sometimes divided into several numbers, in which it is possible to highlight the presence of female characters. Specifically in the periodical $O$ Mosaico, published in 1839, we find five protagonists, whose stories point to the sufferings of women in not being able to achieve their loving feelings because of the eighteenth-century conventions of marriage. This article points to such conventions and reflects on how the readers of that time received these narratives.
\end{abstract}

Keywords: short stories, female characters, nineteenth century. 


\section{REFERÊNCIAS}

ARAUJO, Norberto \& MENDES, Artur Pereira. Aspectos da Tipografia em Portugal. Conferência realizada na Imprensa Nacional de Lisboa em 6 de abril de 1913. Lisboa: Imprensa Nacional, 1914.

MEYER, Marlyse. Folhetim: Uma história. São Paulo: Companhia das Letras, 1996.

MENDONÇA, Simone Cristina. "A conquista do gosto do público leitor: leitores portugueses de prosa de ficção (1768-1822)". Revista Uniletras. Ponta Grossa, Vol. 37, Número 1, pp. 109-120, jan/jun. 2015. Disponível em:

<http://www.revistas2.uepg.br/index.php/uniletras>, consulta em: 01/10/2016.

"Narrativas seriadas em Portugal (Século XIX)". Revista Entreletras. Araguaína/TO, Vol. 7, Número 1, pp. 26-38, jan/jun. 2016. Disponível em: < https://sistemas.uft.edu.br/periodicos/index.php/entreletras/article/view/2167>. Consulta em 30/05/2017.

RODRIGUES, Ernesto. Mágico Folhetim: Literatura e jornalismo em Portugal. Lisboa: Editorial Notícias, 1998.

SANT'ANNA, Benedita de Cássia Lima. Ilustração Brasileira (1854-1855) e a Ilustração Luso-Brasileira (1856, 1858, 1859): uma contribuição para o estudo da imprensa literária em Língua Portuguesa. $327 \mathrm{f}$. Tese (doutorado) - Universidade Estadual de São Paulo, Faculdade de Filosofia, Letras e Ciências Humanas. São Paulo: [s.n.], 2007.

TENGARRINHA, José. História da imprensa periódica portuguesa. Lisboa: Ed. Caminho, 1989.

THÉRENTY, Marie-Ėve. "O longo e o cotidiano. Sobre a dilatação midiática dos romances nos séculos XIX e XX". Trad. Pedro Paulo Garcia Ferreira Catharina. Revista Interfaces, Rio de Janeiro, Vol. 1, Número 22, pp. 117-136, JaneiroJunho, 2015. <Disponível em:

http://www.cla.ufrj.br/images/docs/interfaces/split/22/08_o\%20longo\%20e\%coti diano.pdf>, consulta em 30/09/2015.

VELOSO, Lúcia Maria Mariano. "Elementos para a história da imprensa periódica portuguesa". In: SOUZA, José Manuel de. \& VELOSO, Lúcia Maria Mariano. Historia da imprensa periódica portuguesa: subsídios para uma bibliografia. Coimbra: Coimbra Editora, 1987. (pp. 30-35). 


\section{PERIÓDICOS:}

Analecto de Recreação e erudição. Por ${ }^{* * * *}$ Numero I. Lisboa, na Impressão Regia. M.DCCC.V. Por Ordem Superior. (Biblioteca Nacional de Portugal. P.P.7314 P).

O Mosaico. Jornal d'Instrucção e Recreio cujo lucro é applicado a favor das casas d'Asylo da Infancia desvalida. Volume primeiro. Lisboa. $\mathrm{Na}$ Imprensa Nacional. 1839. <Disponível em: www.orealemrevista.com.br>, consulta a partir de 10 de agosto de 2015.

O Redactor ou ensaios periodicos de litteratura, e conhecimentos scientificos destinados para illustrar a Nação Portugueza. 1803. Lisboa. $\mathrm{Na}$ Impressão Regia. Por Ordem Superior. (Biblioteca Nacional de Portugal. J. 1306 B B B). 